\title{
Innovative startups in 2014
}

\section{Brady Huggett}

O 014 saw a stronger presence of non-US companies on our list $\angle$ of innovative startups receiving the largest A rounds (Table 1). Although Cambridge, Massachusetts, continues to be well represented (four startups on the list), four financings went to non-US firms, up from just one in 2013. The United States continues to dominate the global startup scene (Fig. 1), although the United Kingdom, with 14 A rounds, is resurgent (4 companies in 2012; 10 in 2013). The average size of an A round in Switzerland ( $\$ 21$ million) is greater than anywhere else in the world, including the United States (Table 2).

\begin{tabular}{|c|c|c|c|c|}
\hline Company & Amount raised (millions); date; investors & Scientific founders & Other founders & Technology \\
\hline $\begin{array}{l}\text { Voyager } \\
\text { Therapeutics } \\
\text { (Cambridge, } \\
\text { Massachusetts) }\end{array}$ & $\$ 45 ;$ Feb. 12; Third Rock Ventures & $\begin{array}{l}\text { Krystof Bankiewicz, University of California, San } \\
\text { Francisco; Guangping Gao and Phillip Zamore, } \\
\text { University of Massachusetts Medical School (UMMS); } \\
\text { Mark Kay, Stanford University School of Medicine }\end{array}$ & Not applicable & $\begin{array}{l}\text { Adeno-associated virus (AAV) gene thera- } \\
\text { pies for neurological disease }\end{array}$ \\
\hline $\begin{array}{l}\text { Anokion } \\
\text { (Lausanne, } \\
\text { Switzerland) }\end{array}$ & $\begin{array}{l}\$ 37.6 \text {; May 5; Novartis Venture Funds, } \\
\text { Novo Ventures, Versant Ventures and } \\
\text { private investors }\end{array}$ & $\begin{array}{l}\text { Jeffrey Hubbell and Melody Swartz, Ecole } \\
\text { Polytechnique Fédérale de Lausanne (EPFL) and } \\
\text { University of Chicago; Stephan Kontos, Oscar Buset } \\
\text { and Kristen Lorentz, EPFL }\end{array}$ & $\begin{array}{l}\text { David Lowin, intellectual } \\
\text { property attorney and in- } \\
\text { house counsel }\end{array}$ & $\begin{array}{l}\text { Technology that piggybacks off tolerizing } \\
\text { capacity of erythrocytes by hooking autoim- } \\
\text { mune and allergic antigens to erythrocyte } \\
\text { glycophorin } A \text {, creating tolerizing therapies }\end{array}$ \\
\hline $\begin{array}{l}\text { Piqur } \\
\text { Therapeutics } \\
\text { (Basel, } \\
\text { Switzerland) }\end{array}$ & $\begin{array}{l}\$ 35.6 \text {; April 8; existing investors, new } \\
\text { investors and Versant Ventures }\end{array}$ & $\begin{array}{l}\text { Bernd Giese, Vladimir Cmiljanovic and Matthias } \\
\text { Wymann, University of Basel }\end{array}$ & $\begin{array}{l}\text { Andreas Emmenegger, } \\
\text { Molecular Partners AG }\end{array}$ & $\begin{array}{l}\text { Dual-acting small molecules that strongly } \\
\text { inhibit phosphoinositol 3-kinase while } \\
\text { downregulating mammalian target of } \\
\text { rapamycin for cancer }\end{array}$ \\
\hline $\begin{array}{l}\text { Cidara } \\
\text { Therapeutics } \\
\text { (San Diego) }\end{array}$ & $\begin{array}{l}\$ 32 \text {; June 30; } 5 \text { AM Ventures, Aisling } \\
\text { Capital, Frazier Healthcare, InterWest } \\
\text { Partners and institutional investors }\end{array}$ & $\begin{array}{l}\text { H. Shaw Warren, Harvard University and } \\
\text { Massachusetts General Hospital (MGH) }\end{array}$ & $\begin{array}{l}\text { Kevin Forrest, } 5 \text { AM Ventures; } \\
\text { Kevin Judice, former CEO of } \\
\text { Achaogen Pharmaceuticals }\end{array}$ & $\begin{array}{l}\text { Antimicrobial peptide fusions to neutrophil- } \\
\text { targeting moieties for use as antifungals }\end{array}$ \\
\hline $\begin{array}{l}\text { Dimension } \\
\text { Therapeutics } \\
\text { (Cambridge, } \\
\text { Massachusetts) }\end{array}$ & $\begin{array}{l}\$ 30 ; \text { June 23; Fidelity Biosciences } \\
\text { and OrbiMed Advisors }\end{array}$ & James Wilson, University of Pennsylvania & $\begin{array}{l}\text { Ben Auspitz, Fidelity } \\
\text { Biosciences; Allan Fox, } \\
\text { Foxkiser }\end{array}$ & $\begin{array}{l}\text { AAV gene therapies against hemophilias } \\
\text { and rare diseases }\end{array}$ \\
\hline $\begin{array}{l}\text { Synlogic } \\
\text { (Cambridge, } \\
\text { Massachusetts) }\end{array}$ & $\begin{array}{l}\$ 30 ; \text { Oct. 7; Atlas Venture, New } \\
\text { Enterprise Associates and the Bill and } \\
\text { Melinda Gates Foundation }\end{array}$ & $\begin{array}{l}\text { Jim Collins, Boston University; Timothy Lu, } \\
\text { Massachusetts Institute of Technology (MIT) }\end{array}$ & $\begin{array}{l}\text { Ankit Mahadevia, Atlas } \\
\text { Venture }\end{array}$ & $\begin{array}{l}\text { Bacterial treatments engineered to respond } \\
\text { to gut environment for gastrointestinal dis- } \\
\text { orders and beyond }\end{array}$ \\
\hline $\begin{array}{l}\text { PMV } \\
\text { Pharmaceuticals } \\
\text { (Redwood City, } \\
\text { California) }\end{array}$ & $\begin{array}{l}\$ 30 \text {; Dec. 12; OrbiMed Advisors, } \\
\text { Osage University Partners, InterWest } \\
\text { Partners }\end{array}$ & $\begin{array}{l}\text { Arnold Levine, Institute for Advanced Study and } \\
\text { the Cancer Institute of New Jersey; Thomas Shenk, } \\
\text { Princeton }\end{array}$ & $\begin{array}{l}\text { David Mack, previously with } \\
\text { Alta Partners }\end{array}$ & $\begin{array}{l}\text { p53-MDM2 targeting small molecules from } \\
\text { diversified libraries for treatment of cancer } \\
\text { and infectious diseases }\end{array}$ \\
\hline $\begin{array}{l}\text { Inotrem (Nancy, } \\
\text { France) }\end{array}$ & $\begin{array}{l}\text { \$25.01; March 13; Edmond de } \\
\text { Rothschild Investment Partners, } \\
\text { Sofinnova Partners, BioMedPartners } \\
\text { and Inserm Transfert Initiative }\end{array}$ & $\begin{array}{l}\text { Sebastien Gibot and Marc Derive, University of } \\
\text { Lorraine Medical School in Nancy }\end{array}$ & $\begin{array}{l}\text { Jean-Jacques Garaud, former } \\
\text { head of research and early } \\
\text { development at Roche }\end{array}$ & $\begin{array}{l}\text { Triggering receptor expressed on myeloid } \\
\text { cells } 1 \text { pathway, targeting sepsis }\end{array}$ \\
\hline $\begin{array}{l}\text { CRISPR } \\
\text { Therapeutics } \\
\text { (Basel, } \\
\text { Switzerland) }\end{array}$ & $\$ 25$; April 24; Versant Ventures & $\begin{array}{l}\text { Emmanuelle Charpentier, Hannover Medical School } \\
\text { and Umeå University; Craig Mello, UMMS; Chad } \\
\text { Cowan, Harvard; Matthew Porteus, Stanford University } \\
\text { School of Medicine; Daniel Anderson, MIT }\end{array}$ & $\begin{array}{l}\text { Rodger Novak, formerly global } \\
\text { head of anti-infectives R\&D at } \\
\text { Sanofi; Shaun Foy, formerly of } \\
\text { Nomura Phase4 Ventures }\end{array}$ & CRISPR-Cas9 for genome editing \\
\hline $\begin{array}{l}\text { Raze } \\
\text { Therapeutics } \\
\text { (Cambridge, } \\
\text { Massachusetts) }\end{array}$ & $\begin{array}{l}\$ 24 ; \text { Oct. 14; Atlas Venture, MPM } \\
\text { Capital, MS Ventures, Partners } \\
\text { Innovation Fund, Astellas Venture and } \\
\text { Novartis }\end{array}$ & $\begin{array}{l}\text { Vamsi Mootha, MGH and Harvard Medical School; } \\
\text { Joshua Rabinowitz, Princeton University; David } \\
\text { Sabatini, MIT }\end{array}$ & $\begin{array}{l}\text { Adam Friedman, Atlas } \\
\text { Venture }\end{array}$ & $\begin{array}{l}\text { Small molecules targeting mitochondrial } \\
\text { one-carbon metabolism in cancer }\end{array}$ \\
\hline
\end{tabular}

Massachusetts) Novartis

Source: $\mathrm{BCIQ}$, BioCentury Online Intelligence; company material.

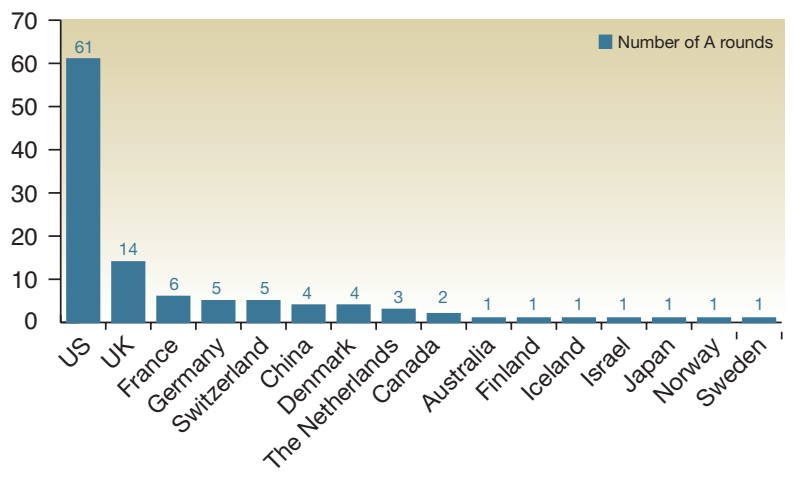

Figure 1 Number of startups by country in 2014. Source: BCIQ: BioCentury Online Intelligence.
Table 2 Total and average A round amounts by country in 2014 .

\begin{tabular}{|c|c|c|}
\hline $\begin{array}{l}\text { Country } \\
\text { (number of rounds) }\end{array}$ & $\begin{array}{c}\text { Total amount raised } \\
\text { (millions) }\end{array}$ & $\begin{array}{c}\text { Average raised per round } \\
\text { (millions) }^{\mathrm{a}}\end{array}$ \\
\hline Switzerland (5) & $\$ 104.1$ & $\$ 20.8$ \\
\hline United Kingdom (14) & $\$ 230.0$ & $\$ 19.2$ \\
\hline United States $(61)^{\mathrm{a}}$ & $\$ 961.6$ & $\$ 17.5$ \\
\hline Canada (2) & $\$ 35.0$ & $\$ 17.5$ \\
\hline China $(4)^{\mathrm{a}}$ & $\$ 49.4$ & $\$ 16.5$ \\
\hline Israel (1) & $\$ 14.0$ & $\$ 14.0$ \\
\hline France (6) & $\$ 74.1$ & $\$ 12.4$ \\
\hline Denmark (4) & $\$ 32.1$ & $\$ 8.0$ \\
\hline Japan (1) & $\$ 8.0$ & $\$ 8.0$ \\
\hline Germany (5) & $\$ 34.4$ & $\$ 6.9$ \\
\hline Sweden (1) & $\$ 5.7$ & $\$ 5.7$ \\
\hline The Netherlands $(3)^{\mathrm{a}}$ & $\$ 5.2$ & $\$ 5.2$ \\
\hline Finland (1) & $\$ 3.8$ & $\$ 3.8$ \\
\hline Iceland (1) & $\$ 2.0$ & $\$ 2.0$ \\
\hline Australia (1) & $\$ 0.9$ & $\$ 0.9$ \\
\hline Norway (1) & $\$ 0.7$ & $\$ 0.7$ \\
\hline
\end{tabular}

Brady Huggett is business editor at Nature Biotechnology. 